\title{
Hazardous effects of titanium dioxide nanoparticles on testicular function in mice
}

\author{
Nobuhiko Miura ${ }^{1}$, Katsumi Ohtani², Tatsuya Hasegawa ${ }^{3}$, Rieko Hojo', Yukie Yanagiba', \\ Tetsuya Suzuki', Megumi Suda' ${ }^{1}$ and Rui-Sheng Wang' ${ }^{1}$ \\ ${ }^{1}$ Division of Health Effects Research, Japan National Institute of Occupational Safety and Health, \\ 6-21-1 Nagao, Tama-ku, Kawasaki, Kanagawa 214-8585, Japan \\ 2Division of Hazard Evaluation and Epidemiology, National Institute of Occupational Safety and Health Japan, \\ 6-21-1 Nagao, Tama-ku, Kawasaki, Kanagawa 214-8585, Japan \\ ${ }^{3}$ Division of Human Environmental Science, Mount Fuji Research Institute, Yamanashi Prefectural Government, \\ 5597-1 Kenmarubi, Kamiyoshida, Fujiyoshida, Yamanashi 403-0005, Japan
}

(Received September 17, 2014; Accepted September 19, 2014)

\begin{abstract}
It has been reported that titanium dioxide nanoparticles $\left(\mathrm{TiO}_{2} \mathrm{NPs}\right)$ show toxicity in organs such as liver, lung, and intestine. There is, however, only a limited number of reports regarding the effect of $\mathrm{TiO}_{2}$ NPs on the male reproductive system. We examined the effect of $\mathrm{TiO}_{2} \mathrm{NPs}_{\text {s }}$ testicular function using mouse model. $\mathrm{TiO}_{2}$ NPs (Aeroxide P25) were evenly dispersed in disodium phosphate solution by sonication. Mice were treated intravenously with $\mathrm{TiO}_{2} \mathrm{NPs}(0,2$, or $10 \mathrm{mg} / \mathrm{kg}$ body weight) once per week for four weeks followed by sacrificing nine days after the last injection. The sperm head numbers and two sperm motion parameters, motile percent (MP) and progressive percent (PP), in the cauda epididymis were evaluated. $\mathrm{TiO}_{2}$ NPs significantly reduced the sperm head numbers in the cauda epididymis and testis, further, the motility ratios of both MP and PP. These results indicated that $\mathrm{TiO}_{2} \mathrm{NPs}_{\text {may }}$ possess hazardous effects on testicular function in mice.
\end{abstract}

Key words: Titanium dioxide nanoparticles, Testicular function, Sperm head numbers, CASA (computer-assisted sperm analysis)

\section{INTRODUCTION}

Titanium dioxide nanoparticles $\left(\mathrm{TiO}_{2} \mathrm{NPs}\right)$ are manufactured worldwide and used in a broad range of applications such as sunscreens and cosmetics, white pigments, food colorant, and antibacterial agent (Dastjerdi and Montazer 2010; Tsuji et al., 2006). Compared to traditionally used $\mathrm{TiO}_{2}$ fine particles (FPs), $\mathrm{TiO}_{2}$ NPs have larger ratio of surface area to volume, therefore, $\mathrm{TiO}_{2} \mathrm{NPs}$ may have potential health risk to humans. With the rapid progression of nanotechnology, the attention about the hazardous effects of $\mathrm{TiO}_{2}$ NPs on health is increasing.

The major issues in the risk assessment of $\mathrm{TiO}_{2} \mathrm{NPs}$ for human health are whether $\mathrm{TiO}_{2} \mathrm{NPs}_{\text {have genotoxic- }}$ ity and potential ability to elevate the cancer risk (Klien and Godnic-Cvar, 2012), and if they have the hazardous potential to the next generation via reproductive toxicity. In our laboratory, one of the ongoing project is the gen- otoxic analysis of $\mathrm{TiO}_{2}$ NPs using the transgenic mouse, named gpt delta mouse, which can detect two different types of mutations, i.e., point mutations and deletions (Nohmi et al., 1996). As the part of our efforts to explore the various effects of $\mathrm{TiO}_{2}$ NPs that may be exerted to human, we are also paying attentions to $\mathrm{TiO}_{2}$ NPsinduced testicular toxicity within the research project. In mammals, there are only limited reports regarding the effect of $\mathrm{TiO}_{2}$ NPs on male reproductive system. $\mathrm{TiO}_{2}$ NPs taken up by mouse Leydig cells reduced the viability and proliferation of these cells (Komatsu et al., 2008). Further, titanium compounds (titanocene dichloride) disrupted the mouse blood-testis barrier (Pereira and Garcia e Costa, 2007). In this study, we investigated the hazardous effects of $\mathrm{TiO}_{2}$ NPs on sperm production and its function using the transgenic mice.

Correspondence: Nobuhiko Miura (E-mail: miuran@h.jniosh.go.jp) 


\section{MATERIALS AND METHODS}

\section{Chemicals and devices}

$\mathrm{TiO}_{2}$ NPs used for experiments were hydrophilic fumed titanium dioxide (Aeroxide ${ }^{\circledR}$ P25) purchased from Sigma-Aldrich (St. Louis, MO, USA). Disodium phosphate (DSP) was purchased from Sigma-Aldrich. Semen analyzer (HTM-IVOS Ver. 12.1M) was the product of Hamilton Thorne Research (Beverly, MA, USA).

\section{Preparation of the $\mathrm{TiO}_{2}$ NP suspension}

After sterilization of $\mathrm{TiO}_{2}$ NPs by dry heat sterilizer $\left(180^{\circ} \mathrm{C}\right.$ for $1 \mathrm{hr}$ ), $\mathrm{TiO}_{2} \mathrm{NPs}$ were suspended in $2 \mathrm{mg} / \mathrm{mL}$ DSP in a glass vial to provide $10 \mathrm{mg} / \mathrm{mL} \mathrm{TiO}_{2}$ NPs suspension (Kobayashi et al., 2009; Naya et al., 2012). $\mathrm{TiO}_{2}$ NPs suspension was sonicated in an ultrasonic water bath (Bransonic 2510; Branson, Danbury, CT, USA) for $30 \mathrm{~min}$. For the vehicle control, sonicated DSP was also prepared. The zeta potential of $\mathrm{TiO}_{2} \mathrm{NPs}$ after sonication was determined using the particle and molecular size analyzer, Zetasizer Nano-ZS (Malvarn, Worchestershire, $\mathrm{UK})$. The $\mathrm{Z}$-average of the $\mathrm{TiO}_{2}-\mathrm{P} 25$ particles in suspension was about 150 d.nm. (data not shown).

\section{Experimental procedures}

Male C57BL/6J gpt delta mice were purchased from Japan SLC (Shizuoka, Japan), and were kept in cages under standard conditions with controlled temperature $\left(24 \pm 1{ }^{\circ} \mathrm{C}\right)$, humidity $(55 \pm 5 \%)$ and light $(12: 12 \mathrm{hr}$ light/ dark cycles, lights on at 08:00 hr). All animals had free access to sterilized commercial pellet diet (CE-2, Clea Japan, Inc., Tokyo, Japan), and sterilized filtered tap water. Mice were adapted for at least 7 days before experiments. Mice ( 8 weeks of age) were intravenously (i.v.) injected with $\mathrm{TiO}_{2}$ NPs suspensions ( 2 or $10 \mathrm{mg} / \mathrm{kg}$ bw) or the vehicle, once a week for 4 consecutive weeks. Nine days after the last injection, mice were sacrificed under carbon dioxide anesthesia. Testicular organs (testes, cauda epididymides, and epididymides except the cauda epididymides) were then separated and weighed for the calculation of relative organ weights to body weights. The right cauda epididymis was immediately analyzed for sperm motility (see "Sperm motility" in this section), and other reproductive organs were stocked in saline at $4^{\circ} \mathrm{C}$ until counting of the sperm head numbers (described in "Sperm head numbers").

The animal experiment was carried out in strict accordance with the recommendations in the guidelines for the care and use of laboratory animals set forth by our Institutional Animal Care and Use Committee of the National Institute of Occupational Safety and Health,
Japan (JNIOSH).

\section{Sperm motility}

Immediately after removal and weighting, the right cauda epididymis was minced with scissors to release sperms in $2 \mathrm{~mL}$ of Medium 199 containing $0.5 \%$ BSA at $37^{\circ} \mathrm{C}$. Sperm suspension was loaded into a capillary microslide (\#HTR1099: $100 \mu \mathrm{m}$ deep; VitroCom Inc., Mountain Lakes, NJ, USA) followed by analyzing the sperm motility with the system of computer-assisted sperm analysis (CASA) using HTM-IVOS (Hamilton Thorne Inc.) (Kato et al., 2001). Two sperm motion parameters, motile percent (MP) and progressive percent (PP), were evaluated in each sample (Ohtani et al., 2013).

\section{Sperm head numbers}

The left cauda epididymis and the left testis were homogenized in saline. Sperm heads of each sample were stained with Hoechst-based dye (IDENT STAIN; Hamilton Thorne Inc.), dropped into a disposable counting chamber (CELL-VU; Millennium Sciences Corp., New York, NY, USA) and mounted on HTM-IVOS. Fluorescence of sperm heads under ultra-violet beam was monitored and counted in RAT-IDENT mode automatically. Data were expressed as total number of sperm heads per tissue sample (Ohtani et al., 2004).

\section{Titanium contents}

Samples of the right testis were digested with nitric acid and hydrogen peroxide. The concentration of titanium (Ti) in each sample was measured using an inductively coupled plasma mass spectrometry (ICP-MS; HP4500, Yokogawa Analytical Systems, Tokyo, Japan) (Miura et al., 2013). The Ti concentration was determined at the mass numbers of $47 \mathrm{~m} / \mathrm{z}$.

\section{Statistical analysis}

Data were analyzed by one-way ANOVA. Statistical significance of difference between control and $\mathrm{TiO}_{2} \mathrm{NPs}-$ treated groups was determined with Dunnett's test. In all cases, $p<0.05$ was considered statistically significant.

\section{RESULTS}

The body weights and the testicular organ weights (testes, cauda epididymides, and epididymides except the cauda epididymides) showed no significant differences among the control group and the $\mathrm{TiO}_{2}$ NPs-treated groups (Table 1). The relative ratio (\%) of organ weights per body weights (in parentheses of Table 1) also showed no significant differences. Therefore, $\mathrm{TiO}_{2} \mathrm{NPs}$ doses used in 
Testicular damage by titanium dioxide nanoparticles

Table 1. Body weights and testicular organ weights of mice treated with $\mathrm{TiO}_{2} \mathrm{NPs}$.

\begin{tabular}{lcccc}
\hline Group name & Body weight & Testes & Epididymides ${ }^{1)}$ & Cauda epididymides \\
\hline Control (DSP) & $25.7 \pm 2.2$ & $0.200 \pm 0.012$ & $0.046 \pm 0.010$ & $0.027 \pm 0.005$ \\
$(\mathrm{n}=5)$ & & {$[0.784 \pm 0.100]$} & {$[0.178 \pm 0.031]$} & {$[0.104 \pm 0.019]$} \\
\hline $\mathrm{TiO}_{2} \mathrm{NPs}(2 \mathrm{mg} / \mathrm{kg})$ & $24.2 \pm 0.9$ & $0.200 \pm 0.011$ & $0.040 \pm 0.006$ & $0.023 \pm 0.002$ \\
$(\mathrm{n}=4)$ & & {$[0.828 \pm 0.033]$} & {$[0.166 \pm 0.031]$} & {$[0.097 \pm 0.011]$} \\
\hline $\mathrm{TiO}_{2} \mathrm{NPs}(10 \mathrm{mg} / \mathrm{kg})$ & $25.0 \pm 1.0$ & $0.205 \pm 0.004$ & $0.050 \pm 0.007$ & $0.025 \pm 0.002$ \\
$(\mathrm{n}=4)$ & & {$[0.819 \pm 0.049]$} & {$[0.201 \pm 0.022]$} & {$[0.102 \pm 0.007]$} \\
\hline
\end{tabular}

The number (n) of animals in each group is shown in the column of "Group name". Weights are represented as gram. The relative ratio (\%) of organ weights per body weights are shown in the parentheses under the organ weights (g). Values are means \pm S.D. 1) Weights of the epididymides except the cauda epididymides are shown.

this experiment did not affect these parameters after treatment of 4 weeks.

However, the sperm head numbers of the left cauda epididymis were decreased markedly by $\mathrm{TiO}_{2} \mathrm{NPs}$ injection, to less than half of the control level (Fig. 1-a). This effect was observed even in the low dose group. In the left testis, the sperm head numbers also showed remarkable reduction compared to the control group (Fig. 1-b), a result similar to that of the left cauda epididymis. It is well known that mammalian sperm cells mature while passing through the cauda epididymides, whereas the sperm cells in testes are almost immature (Seligman et al., 1992). Therefore, $\mathrm{TiO}_{2}$ NPs may affect both of these stages by the injection doses. We further analyzed the quality of sperm cells. Two sperm motion parameters, motile percent (MP) and progressive percent (PP), were evaluated. As a result, $\mathrm{TiO}_{2}$ NPs markedly reduced these sperm motion parameters (Fig. 2-a and -b). These results indicate that $\mathrm{TiO}_{2}$ NPs induce hazardous effect on testicular system, i.e., both quantity of sperm head numbers and quality of sperm cells.

The titanium concentrations of the right testis were determined, but the values were only trace amount, although it seemed to increase by a small amount in the high dose group of $\mathrm{TiO}_{2}$ NPs injection (Fig. 3).

\section{DISCUSSION}

Several studies reported that $\mathrm{TiO}_{2} \mathrm{NPs}$ taken up by mouse Leydig cells reduced the viability and proliferation of these cells; further, titanium compounds (titanocene dichloride) disrupted the mouse blood-testis barrier. In this study, we examined the effect of $\mathrm{TiO}_{2} \mathrm{NPs}$ on testicular function using mouse model. Our data indicated that $\mathrm{TiO}_{2} \mathrm{NPs}$ apparently reduced testicular function evaluated by several parameters, the sperm head numbers (Fig. 1)
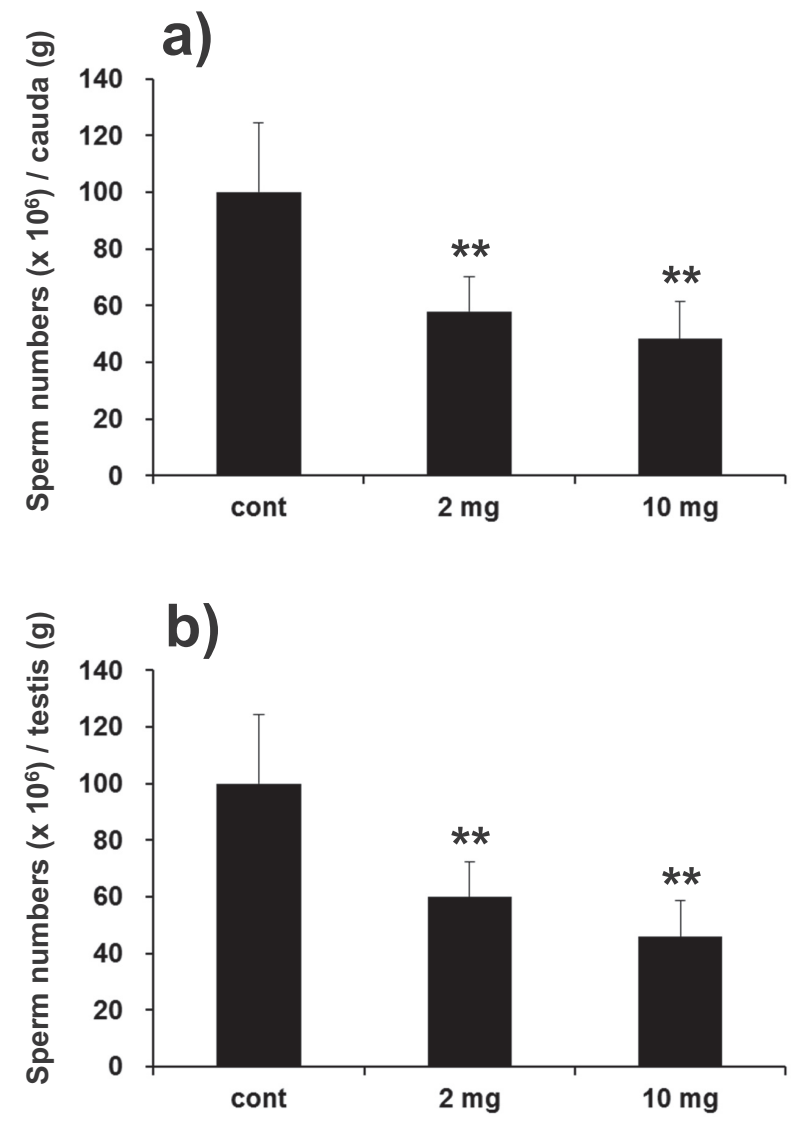

Fig. 1. Effect of $\mathrm{TiO}_{2} \mathrm{NPs}$ on sperm head numbers. Mice were injected with $\mathrm{TiO}_{2}$ NPs suspensions ( 2 or $10 \mathrm{mg} / \mathrm{kg}$ bw, i.v.) once a week for 4 consecutive weeks. Control group was received the vehicle (DSP). Analyses were performed nine days after the last injection. The left cauda epididymis and the left testis were homogenized in saline followed by counting the sperm head numbers by HTM-IVOS. a) cauda epididymis; b) testis. $* *$, significantly different from control $(\mathrm{p}<0.01)$. 


\section{N. Miura et al.}
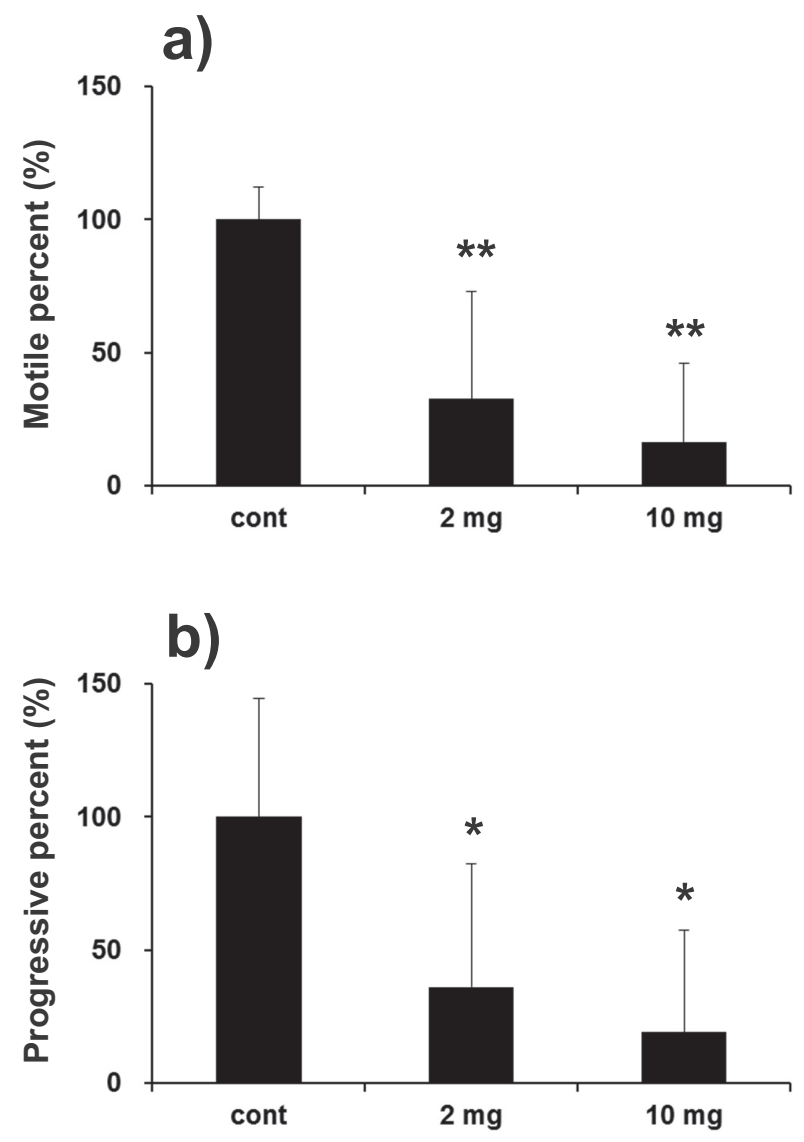

Fig. 2. Effect of $\mathrm{TiO}_{2}$ NPs on sperm motility. Organ samples were collected from the same mice as described in Fig. 1. Immediately after removal of organ samples from mouse, the right cauda epididymis was minced in $2 \mathrm{~mL}$ of Medium 199 containing $0.5 \%$ BSA. The sperm motility was analyzed by HTM-IVOS. Two sperm motion parameters, motile percent (MP) and progressive percent (PP), were examined. a) MP; b) PP. $*, * *$, significantly different from control $(*: \mathrm{p}<0.05$; $* *: \mathrm{p}<0.01)$

and the sperm motility ratios (Fig. 2) in the testis and the cauda epididymis, in the doses which did not affect body weight and testicular organ weights (Table 1). Therefore, $\mathrm{TiO}_{2}$ NPs may possess the hazardous effects on testicular functions in both quantitative and qualitative ways.

It is not known why the sperm head number reduction occurred by $\mathrm{TiO}_{2}$ NPs injection; $\mathrm{TiO}_{2}$ NPs translocated from blood to the testicular tissue may interfere the spermatogenesis at two points; one is to induce damage(s) to the spermatogenic cells, resulting in the decrease of the number of mature sperm cells; another one may be the direct attack to the mature sperm cells. In order to elucidate the mechanisms underlying the testicular toxicity

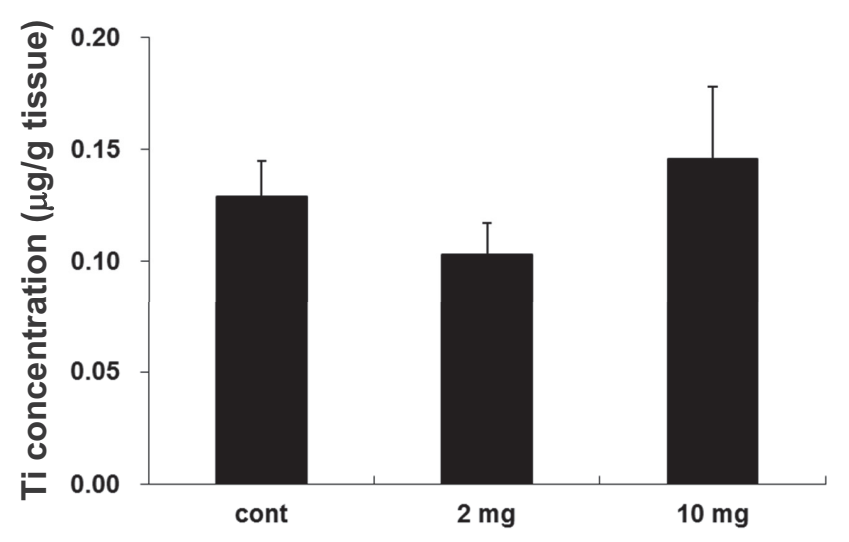

Fig. 3. Concentrations of titanium in the testis. Organ samples were collected from same mice as described in Fig. 1. Samples of the right testis were digested with nitric acid. Titanium contents were measured using ICP-MS.

of $\mathrm{TiO}_{2}$ NPs, a series of experiments are going to be conducted.

Sperm cells in the testes are almost immature, and they are getting mature while passing through the cauda epididymides (Seligman et al., 1992). Because the motility of mature sperm cells obtained from the cauda epididymides was inhibited by $\mathrm{TiO}_{2}$ NPs injection, $\mathrm{TiO}_{2} \mathrm{NPs}$ is considered to affect not only the immature sperm cells in the testes but also the mature one stocked in the epididymides. Nevertheless, it is necessary to clarify the inhibitory mechanism of the testicular function by $\mathrm{TiO}_{2} \mathrm{NPs}$ in the future experiments.

\section{ACKNOWLEDGMENT}

This work was supported by grant-in-aid for project research (N-P24-02) from JNIOSH.

Conflict of interest---- The authors declare that there is no conflict of interest.

\section{REFERENCES}

Dastjerdi, R. and Montazer, M. (2010): A review on the application of inorganic nano-structured materials in the modification of textiles: focus on anti-microbial properties. Colloids Surf. B Biointerfaces, 79, 5-18.

Kato, M., Fukunishi, K., Ikegawa, S., Higuchi, H., Sato, M., Horimoto, M. and Ito, S. (2001): Overview of studies on rat sperm motion analysis using a Hamilton-Thorne Sperm Analyzer--collaborative working study. J. Toxicol. Sci., 26, 285-297.

Klien, K. and Godnic-Cvar, J. (2012): Genotoxicity of metal nano- 
Testicular damage by titanium dioxide nanoparticles

particles: focus on in vivo studies. Arh. Hig. Rada Toksikol., 63, 133-1345.

Kobayashi, N., Naya, M., Endoh, S., Maru, J., Yamamoto, K. and Nakanishi, J. (2009): Comparative pulmonary toxicity study of nano-TiO(2) particles of different sizes and agglomerations in rats: different short- and long-term post-instillation results. Toxicology, 264, 110-118.

Komatsu, T., Tabata, M., Kubo-Irie, M., Shimizu, T., Suzuki, K., Nihei, Y. and Takeda, K. (2008): The effects of nanoparticles on mouse testis Leydig cells in vitro. Toxicol. In Vitro, 22, 18251831.

Miura, N., Ashimori, A., Takeuchi, A., Ohtani, K., Takada, N., Yanagiba, Y., Mita, M., Togawa, M. and Hasegawa, T. (2013): Mechanisms of cadmium-induced chronotoxicity in mice. J. Toxicol. Sci., 38, 947-957.

Naya, M., Kobayashi, N., Ema, M., Kasamoto, S., Fukumuro, M., Takami, S., Nakajima, M., Hayashi, M. and Nakanishi, J. (2012): In vivo genotoxicity study of titanium dioxide nanoparticles using comet assay following intratracheal instillation in rats. Regul. Toxicol. Pharmacol., 62, 1-6.

Nohmi, T., Katoh, M., Suzuki, H., Matsui, M., Yamada, M., Watanabe, M., Suzuki, M., Horiya, N., Ueda, O., Shibuya, T.,
Ikeda, H. and Sofuni, T. (1996): A new transgenic mouse mutagenesis test system using Spi- and 6-thioguanine selections. Environ. Mol. Mutagen., 28, 465-470.

Ohtani, K., Yamazaki, S., Kubota, H., Miyagawa, M. and Saegusa, J. (2004): Comparative investigation of several sperm analysis methods for evaluation of spermatotoxicity of industrial chemical: 2-bromopropane as an example. Ind. Health, 42, 219-225.

Ohtani, K., Yanagiba, Y., Ashimori, A., Takeuchi, A., Takada, N., Togawa, M., Hasegawa, T., Ikeda, M. and Miura, N. (2013): Influence of injection timing on severity of cadmium-induced testicular toxicity in mice. J. Toxicol. Sci., 38, 145-150.

Pereira, M.L. and Garcia e Costa, F. (2007): The blood-testis barrier as a target of some chemotherapeutic agents. Chemotherapy, 53, 446-448.

Seligman, J., Kosower, N.S. and Shalgi, R. (1992): Effects of caput ligation on rat sperm and epididymis: protein thiols and fertilizing ability. Biol. Reprod., 46, 301-308.

Tsuji, J.S., Maynard, A.D., Howard, P.C., James, J.T., Lam, C.W., Warheit, D.B. and Santamaria, A.B. (2006): Research strategies for safety evaluation of nanomaterials, part IV: risk assessment of nanoparticles. Toxicol. Sci., 89, 42-50. 